www.jmscr.igmpublication.org

Impact Factor (SJIF): 6.379

Index Copernicus Value: 79.54

ISSN (e)-2347-176x ISSN (p) 2455-0450

crossrefDOI: https://dx.doi.org/10.18535/jmscr/v6i11.42

Journal Of Medical Science And Clinical Research

\title{
Analysis of Turnaround Time for Issuance of Blood Products in Emergency: A Prospective Study in a Tertiary Care Centre in Jammu
}

\author{
Authors \\ Mitali Sharma, Swati Arora, Ankur Malhotra
}

\begin{abstract}
Background: Quality indicators in transfusion medicine are necessary for patient safety and customer satisfaction. The turnaround time (TAT) of issuing red blood cells (RBCs) has emerged as one of the important quality indicator.

Aim: To evaluate the turnaround time (TAT) for the blood components from the time the blood request is received in the blood bank to issuance of the blood. Cases with delayed TATs were further analyzed to determine potential causes for the delays.

Material and Method: A total of 104 emergency cases were issued blood using immediate spin cross match (ISCM) technique over a period of three months. The TAT was evaluated by a team of investigators using standardised electronic timers. Standard TAT was fixed as 30 minutes. Reasons for delayed TAT were found out and analysed

Result: Most of the emergency requests were from surgical departments (72\%). Majority of the requests were completed within 11-35 min. 41.34\% requests had TAT above standard of 30 minutes. Main causes for delay were improper filling of the blood request and improper labelling of the samples, multiple component demands, short staffing, inadequate or lysed sample.

Conclusion: In spite of the continual emphasis on quality control, it is a challenge to maintain Turnaround Time within acceptable limits even in emergencies. At the physician's end, it is important to emphasise on the importance of proper filling of request form and sample labelling. In lab, Blood bank personnel should be trained to handle urgent requests by assigning them priority. Moreover, continued education of hospital staff is needed to improve TATs.

Keywords: Turnaround time, immediate spin cross match, quality indicator, root cause analysis , blood transfusion.
\end{abstract}

\section{Introduction}

Turnaround time (TAT) is an important quality indicator in clinical laboratories. The timeliness of blood issuances is very important for efficient and satisfactory laboratory services, especially during surgical urgency or emergency ${ }^{[11]}$. TAT is one of the 10 Quality Indicators for Blood Banks. It is defined as the time taken to be calculated from the time the request/ sample is received in the blood bank till the blood is cross matched/ reserved and available for transfusion. Blood Banks are required to set upper limits for routine and emergency issues separately ${ }^{[13]}$.

Since the nature of patients served in transfusion medicine vary in many ways from routine laboratory services, service quality and analytical quality should be concurrently sought and are equally important here. From a clinician`s point of 
view, receiving required blood units on time might be the most important performance indicator of the blood bank. For emergency services, delay of even few minutes in availing blood can make a whole difference. It is well implied that monitoring and improvement of TAT is beneficial and highly recommended for transfusion services. Moreover, routine monitoring of quality indicators including TAT in the transfusion medicine improves patient safety and customer satisfaction $^{[10,12]}$.The first step for reducing TAT towards a desired goal should be finding out variation of the TAT for different services, products and schedules. It also needs identifying the causes of delay in TAT and taking corrective measures to eliminate them. Those causes with greatest effect should be addressed first, considering the constraints of time, manpower and resources to handle all issues at once ${ }^{[14]}$.

Our institution is a tertiary care medical college. Although there are various steps from the most crucial is the time taken from a request being placed for transfusion and issue of the compatible blood unit for the Immediate Spin Crossmatch (ISCM). We also tried to identify the factors which lead to increased TAT in our Centre in issuing blood and blood components.

\section{Material and Methods}

This was a prospective study conducted in department of Blood Bank, ASCOMS \& Hospital, Sidhra, Jammu from over a period of three months from $1^{\text {st }}$ January 2018 to $31^{\text {st }}$ march 2018 . TAT was defined from time of reception of an issue request to time at which the blood unit was handed over to attendant of the patient.

All emergency requests for Packed Red Cells (PRC), Fresh Frozen Plasma (FFP) and Platelet concentrate were included during this period. Cases excluded were those who needed Anti human globulin (AHG) crossmatch, elective cases, crossmatch for reservation and units that required additional special handling (e.g. washing).
The process of issuing blood was analysed and was divided in various phases

1. Recurring of issue request and sample and allocation to a technician for crossmatching which is entered in the allotment register with date and time.

2. Transport of sample to testing site.

3. Selection of blood unit and compatibility testing.

4. labelling and transport to issue counter

5. Reception by attendant who signs the receipt with date and time.

Starting and stopping times were recorded by the study team (1 in sample reception, 1 in blood allotment room, 1 in crossmatch room, 1 in issue counter) with the help of timer. Standard turnaround time was fixed as 30 minutes for issuing blood units after immediate spin crossmatch from previous literature. Data collection was done in real time in prepared worksheet. The nature of the study was not disclosed to the staff involved in sample processing and compatability testing to avoid bias in result. Synchronised electronic timers were employed to ensure integrity of the recorded times.

Data was recorded only during morning (8 am $2 \mathrm{pm})$ and wait (2pm- $7 \mathrm{pm})$ shifts. Reasons for delay were noted in prolonged TAT. Type of product and number of product needed was recorded from the request.

\section{Statistical Analysis}

Data was entered in excel sheets daily. Analysis was done in SPSS version 16. Data of continuous variables are reported as mean (95\% confidence interval $[\mathrm{CI}])$. Significance was accepted at probability value of 0.05 or less.

\section{Results}

104 cases were issued after ISCM during the study period of three months. Majority (72\%) of cases belonged to surgical specialities which included Surgery, Obstetrics and gynaecology, orthopaedics, and paediatric surgery. Various 
other non surgical (28\%) which needed blood on emergency included medicine, haematology, nephrology, gastroenterology etc.

Figure 1 shows distribution of cases according to the time taken for issue and it shows a wide distribution of cases according to TAT. $74(71.15 \%)$ of total cases fall between 11 to 35 minutes.

Out of 104 cases, 43(41.34\%) cases fall above 30 minute of TAT, extended beyond standard TAT. These cases needed to be further examined to find out reasons for the delay. Mean TAT was found to be 28.72 and SD was found to be 8.15 . As shown in figure 2 mean TAT for samples during morning and wait shift were not significantly different (Analysis of variance; ANOVA $\mathrm{p}=0.628$ ).

TAT is more for FFP than for PCV and Platelet concentrates, since FFPs are issued as multiple units and need time for thawing (table-1).

Main reasons behind increased TAT as determined by root cause analysis for each case are enlisted in Table 2. Some reasons were found $t$ be frequently involved like multiple component demand for a patient, thawing of FFP, issues with attender availability.

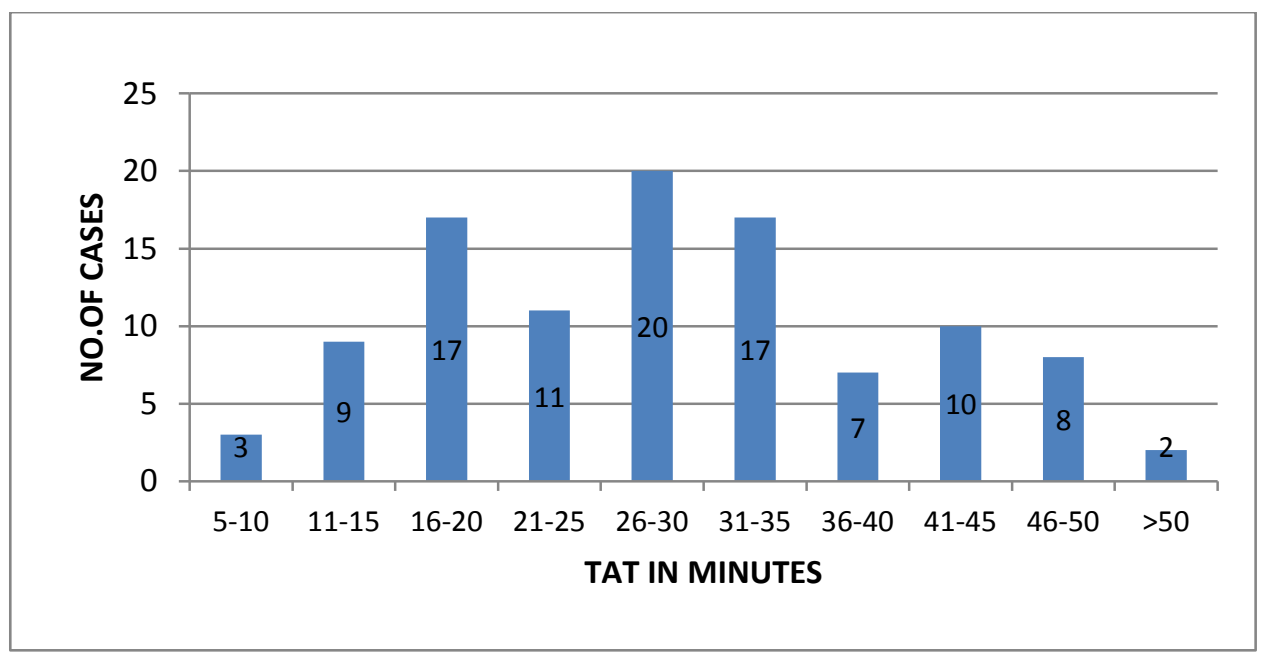

Figure 1: TAT distribution according to number of cases.

Table 1: Distribution of TAT according to number of components

\begin{tabular}{|l|c|c|}
\hline COMPONENT & NO. OF CASES & MEAN \\
\hline PRC (single) & 24 & 28.83 \\
\hline PRC (multiple) & 8 & 32.61 \\
\hline FFP (multiple) & 11 & 38.15 \\
\hline PC (multiple) & 12 & 27.72 \\
\hline MULTIPLE COMPONENTS & 15 & 39.25 \\
\hline
\end{tabular}

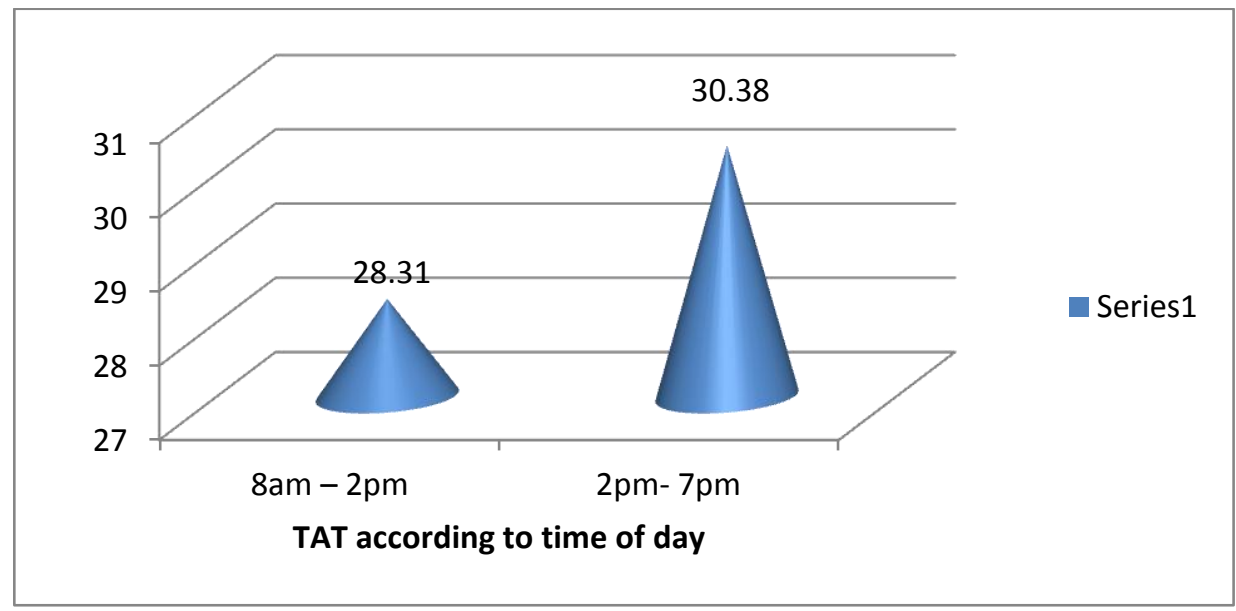

Figure 2: Distribution of TAT according to shifts of the day 
Table 2: Root cause analyses of delay in TAT

\begin{tabular}{|c|c|c|}
\hline $\begin{array}{l}\text { TAT } \\
\text { (in minutes) }\end{array}$ & NO OF ISCM & CAUSES FOR DELAY \\
\hline $31-35$ & 17 & $\begin{array}{c}\text {-multiple blood requests } \\
\text {-sample not labelled } \\
\text {-hospital attender unavailable }\end{array}$ \\
\hline $36-40$ & 7 & $\begin{array}{c}\text {-thawing of FFP } \\
\text {-multiple blood requests } \\
\text {-hospital attender shortage }\end{array}$ \\
\hline $41-45$ & 10 & $\begin{array}{l}\text {-instrument breakdown } \\
\text {-leakage of units } \\
\text {-lysed sample } \\
\text {-request not found } \\
\text {-thawing of FFP }\end{array}$ \\
\hline $46-50$ & 8 & $\begin{array}{c}\text {-sample not found } \\
\text {-discrepancy } \\
\text {-Lysed sample } \\
\text {-sample not labelled } \\
\text {-searching for units }\end{array}$ \\
\hline More than 50 & 2 & $\begin{array}{c}\text {-lysed sample } \\
\text {-multiple blood requests } \\
\text {-discrepancy }\end{array}$ \\
\hline
\end{tabular}

\section{Discussion}

Intraoperative blood loss can occur unpredictably and the need for blood transfusion might be necessary in such situations. Among the multitude of daily administrative problems faced by modern hospitals today, prolonged TAT of laboratory investigation is a crucial one, especially in emergency cases, which affects patient care as well as patient satisfaction adversely. Since TAT involves both physician satisfaction and quality of laboratory services it can be considered a very crucial indicator and been used since $1980 \mathrm{~s}^{[4,3]}$.

In the present study the mean TAT is found to be 28.72 minutes which is less than 30 minutes which was taken as standard time for the study and $\mathrm{SD}$ is $8.15 \mathrm{~min}$.

A study by Bruce et al. noticed that median turnaround time of $30 \mathrm{~min}$ for $\mathrm{RBC}$ units to be issued and $35 \mathrm{~min}$ for delivery of RBC unit to the operating room following an emergency request to the blood bank are reported by many authors including Q- Probe College of American Pathologists ${ }^{[6]}$. Richard et al. reported that time needed to perform $\mathrm{ABO}$ and $\mathrm{RH}$ typing, screening and Immediate spin crossmatching and then to issue blood cells for transfusion is 30-90 min depending on system ${ }^{[15]}$. Considering above facts we set the limit of 30 minutes as appropriate in our study. TATs which were extended beyond this limit were analysed to find the possible reasons. Comparisons of TATs among institutions technologies used for sample processing and compatibility testing should be considered. Studies which do not include multiple product issue report have lower TAT. Colt M, Mc Clain et al. compared the mean TATs at the two institutions for orders of RBCs. They found TAT for emergency blood issue were $10 \pm 3.8 \mathrm{~min}$ in one centre and $14 \pm 7.2 \mathrm{~min}$ in another ${ }^{[12]}$.

In another study by Lee AJ et al. mean (SD) preparation to issuance time (14[7.8] $\mathrm{min})$ contributed more to the overall TAT than did mean (SD) request to preparation time (4.5[7.5] min). Prolonged compatibility testing and delayed courier arrival contributed to TAT delay ${ }^{[11]}$.

In Ramanathan et al. study, 125 cases were studied in 1 month, 59(47.2\%) were falling above 30 minutes i.e. extended beyond TAT. Mean TAT for single PRC unit issued was 29.91minutes and for multiple PRC unit was found to be 34.86 minutes ${ }^{[14]}$. 
Although statistically insignificant $(\mathrm{p}=0.628)$, the mean TAT was shorter during the morning shift than the wait shift. The request to preparation period contributed to TAT delay. Prolonged compatibility testing might be due to short staffing (inadequate no. of workers). In our blood bank, 4 full-time employees work in morning duty and 2 full time employees on the wait shift. In Lee AJ et al mean (SD) TAT was longer during the hours of 6:00 pm to 9:00pm than during the hours of 9:00am to $6: 00 \mathrm{pm}$ due to short staffing ${ }^{[11]}$. In another study, Ramanathan et al, TAT was analysed during 3 shifts but difference was not found $t o$ be satistically significant $(p=0.86)^{[14]}$.

Study by Weiskopf et al. determined TAT for procedure which involved previously crossmatched blood units which needed only issue to the operating room. $82 \%$ of units reached operating room within 2 minutes of request, 91\%arrived within 3 minutes and 100\%arrived within 4 minutes ${ }^{[8,7]}$.

Root cause analysis demonstrated four causes mainly but we could not determine the proportion of their contribution each to the overall delay. These are improper filling of the blood request and improper labelling of the samples, multiple component demands, short staffing, Inadequate or lysed sample.

Stoler et al. performed an interventional study with a hypothesis that delays occurred because of disproportion between the patient sample work load and the number of employees available in the stat pre analytics area were found to be an important contributing factor for delayed $\mathrm{TAT}^{[5]}$.

Reason for delayed TAT in our setting can also be lack of automated facilities for sample transport and manual transportation. The issue is identified by many similar studies in huge facilities with high workload ${ }^{[9,2]}$. Automation is reported to have significantly decreased TAT also ${ }^{[1]}$.

Limitations of the study may include that although recording the event times, arrangements were made to keep the staff unaware of the objective; some knowledge about being obsessed may have escaped. Still, the study helped us to assess the efficiency of our work flow and monitoring services in current scenario ${ }^{[16]}$.

\section{Conclusion}

A wide variation in TAT is observed in our study and there were many cases that extended beyond the standard TAT. Root cause analysis can help us develop strategies to narrow the TAT to minimum standard. Strict adherence to SOPs, proper education of clinical staff by demonstration regarding requesting blood units and sample labelling, better work force distribution can help us achieve our goals. Reassignment of massive transfusion protocol may be under primary consideration. This study will act as a benchmark for TAT in issuing blood units in our blood bank.

\section{Bibliography}

1. Ashraf Dada Daniela Beck Gerd Schmitz. Automation and Data Processing in Blood Banking Using the Ortho AutoVue Innova System. Transfus Med Hemother.

2. Binita Goswami, Bhawna Singh, Ranjna Chawla, V.K.Gupta, V.Mallika. Turn Around Time (TAT) as a Benchmark of Laboratory Performance. Ind J Clin Biochem. 2010;25:376-379

3. Bloch DM. Computer-generated management tools for the clinical pathology laboratory. II. Computer-generated graphic work flow. J Med Syst. 1982;6:305-10.

4. Breil B, Fritz F, Thiemann V, Dugas M. Mapping turnaround times (TAT) to a generic timeline: a systematic review of TAT definitions in clinical domains. BMC Med Inform Decis Mak. 2011;11:34.

5. Brie A. Stotler, Alexander Kratz. Determination of Turnaround Time in the Clinical Laboratory. Am J Clin Pathol. 2012;138:724-729.

6. Bruce A. Jones, MD; David A. Novis. Nongynecologic Cytology Turnaround Time. Arch Pathol Lab Med. 2001;125:1279-1284. 
7. Cheng G, Chiu DS, Chung AS, et al. A novel system for providing compatible blood to patients during surgery: "selfservice" electronic blood banking by nursing staff. Transfusion. 1996;36:347350 .

8. Cox C, Enno A, Deveridge S. Remote electronic blood release system. Transfusion. 1997;37:960-964.

9. Jalili M, Shalileh K, Mojtahed A, Mojtahed M, MoradiLakeh M. Identifying Causes of Laboratory Turnaround Time Delay in the Emergency Department. Arch Iran Med. 2012;15:759-763.

10. Kh.Memtombi Devi, A.Barindra Sharma, L.Dorendro Singh, Ksh.Vijayanta, S.T.Lalhriatpuii, A.Meina Singh. Quality Indicators of Blood Utilization in a Tertiary Care Centre in the North-Eastern India. Journal of Dental and Medical Sciences. 2014;13:50-52.

Laboratory Medicine 0:0:1-5;48;277-281

11. Lee AJ, Kim SG, Analysis of Turnaround Time for Intraoperative Red Blood Cell issues: A Single-Center Study

12. McClain CM, Hughes J, Andrews JC, Blackburn J, Sephel S, France D, Viele M, Goodnough LT, Young PP. Blood ordering from the operating room: turnaround time as a quality indicator. Transfusion. 2013;53:41-8.

13. Quality indicators of blood bank. www.nabh.co.>H.DOC >QIBB

14. Ramanathan T, Shaiji. P.S, K.C. Usha. Turnaround time for issuing blood products in emergency-a prospective real time study in a regional blood transfusion centre. International Journal of Contemporary Medical Research 2017;4(3):688-691.

15. Richard B. Weiskopf, Mary Webb, BS; Deena Stangle, BA; Gunter Klinbergs, Pearl Toy. A Procedure for Rapid Issue of Red Cells for Emergency. Use. Arch Pathol Lab Med. 2005;129:492-496.
16. Robin T. Vollmer, MD. Analysis of Turnaround Times in Pathology. Am J Clin Pathol. 2006;126:215-220. 